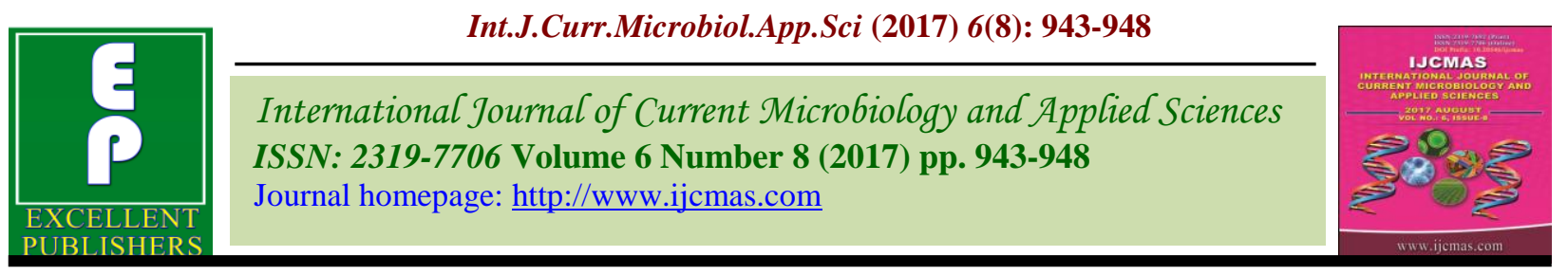

Original Research Article

https://doi.org/10.20546/ijcmas.2017.608.116

\title{
Extraction and Characterization of Pectin from Fruit Waste
}

\author{
P.S. Panchami* and S. Gunasekaran \\ Department of Agricultural Microbiology, Tamil Nadu Agricultural University, \\ Coimbatore, Tamil Nadu, India \\ *Corresponding author
}

A B S T R A C T

Keywords

Pectin, Fruit waste, Extraction.

Article Info

Accepted:

14 June 2017

Available Online:

10 August 2017
Fruit wastes such as citrus peel, mango peel, apple pomace and banana peel were collected from fruit juice manufacturing industries and were subjected to pectin extraction. The results revealed that citrus peel is containing higher pectin content of about $24.5 \%$. Characterization of different fruit waste were also done

\section{Introduction}

India is the third major producer of fruits and vegetables and ranks next to Brazil and China respectively, in the world. In recent years, the effect of fruit waste is one of major concern contributing to global environmental burden. For instance, the fraction of discarded materials in the majority of fruit processing industries is typically very high (Laufenberg et al., 2003; Parfitt et al., 2010) depending on the location and method of harvest (e.g. mango $30-50 \%$, banana $20 \%$, pomegranate $40-50 \%$ and citrus 30-50\%).The food processing industry generates approximately 45 per cent of total industrial organic pollution (Akerberg and Zacchi, 2000). These organic wastes are rich in biodegradable materials, making them suitable substrate for biotechnological production of biochemicals. (Anuradha et al., 1999). Bioconversion of carbohydrate waste is receiving increased attention in view of the fact that these wastes can act as substrate for the production of useful biomaterials and chemical intermediates (Baker et al., 1998).

Pectins are complex polysaccharides consisting mainly of galacturonic acid units being linked by $\alpha-(1 \rightarrow 4)$ linkages. Pectin is a polysaccharide widely used in food and pharmaceutical industries is as thickening and gelling agents (May, 1990).

Extraction is the most important process in the pectin production. Pectic substances are usually extracted by chemical or enzymatic methods, with a process of physical and chemical multiple stages, in which involves hydrolysis, extraction and solubilization of macromolecules (Pagan et al., 2001). Extraction with hot water is the simplest and oldest method for recovery of pectic substances from plant tissues (Hermann, 
1919). The extraction of pectin involves the hydrolysis of insoluble protopectin into soluble pectins and then leaching them out of fruit tissues.

The extraction of pectin from fruit peels using weak organic acid such as citric acid has been intensively conducted in recent studies (Minjares-Fuentes et al., 2014; Kulkarni et al., 2010; Pinheiro et al., 2008). This work aims to extract and characterize pectin from different fruit wastes.

\section{Materials and Methods}

\section{Sample collection}

Fruit wastes such as citrus peel, mango peel, apple pomace and banana peel were collected (approximately 5kgs) from different locations in and around the fruit juice manufacturing industries in Coimbatore. Collected fruit wastes were dried in open to eliminate the available moisture and mixed thoroughly. The homogenized samples were powdered, kept separately and used for periodical analyses

\section{Extraction of pectin from fruit wastes}

From the fruit wastes of orange, mango, apple and banana, pectin was extracted as per the following procedure. About fifty gram of fruit waste was ground and $300 \mathrm{ml}$ of $0.1 \mathrm{~N} \mathrm{HCL}$ was added. The contents were boiled for 30 min. and filtered under suction. To the residue, boiling water was added and filtrate was collected. The process was repeated with $0.05 \mathrm{~N} \mathrm{HCL}$ and $0.3 \mathrm{~N} \mathrm{HCL}$ and filtrates collected.

All the filtrates were pooled and the volume was made up to $500 \mathrm{ml}$. From this $200 \mathrm{ml}$ was transferred into a beaker and $250 \mathrm{ml}$ of water was added. The acid present in the filtrate was neutralized by adding $1 \mathrm{~N} \mathrm{NaOH}$ using phenolphthalein indicator and allowed to stand for $24 \mathrm{~h}$. Fifty $\mathrm{ml}$ of $1 \mathrm{~N}$ acetic acid was added and after 5 min. $25 \mathrm{ml}$ of $1 \mathrm{~N}$ calcium chloride was added with stirring and allowed to stand for an hour. The contents were then boiled for $2 \mathrm{~min}$. and filtered through a pre weighed Whatman No. 1 filter paper. Finally the precipitate was washed with boiling water until the filtrate was free from chloride.

For estimating the total pectin content, the filter paper with calcium pectate was transferred to pre weighed dish and dried at $100^{\circ} \mathrm{C}$ overnight, cooled and dry weight determined (Manickam and Sadasivam, 1996).

Weight of calcium pectate $\times 100 \times 500$ $\%$ Calcium pectate $=$

$\mathrm{ml}$ of filtrate taken $\times$

Weight of sample taken for estimation

\section{Calorimetric determination of pectin}

About $100 \mathrm{mg}$ of pectin was dissolved in 100 $\mathrm{ml}$ of $0.05 \mathrm{~N} \mathrm{NaOH}$ and allowed to stand for $30 \mathrm{~min}$. to deesterify the pectin. From this 2 $\mathrm{ml}$ of the solution was taken and made upto $100 \mathrm{ml}$ with water. Two $\mathrm{ml}$ of deesterified pectin solution was pippetted and $1 \mathrm{ml}$ of carbazole reagent was added. A white precipitate was formed.

To this $12 \mathrm{ml}$ of conc. $\mathrm{H}_{2} \mathrm{SO}_{4}$ was added with constant stirring. The tubes were then closed with rubber stopper and allowed to stand for $10 \mathrm{~min}$. to develop the colour. To set the blank, $1 \mathrm{ml}$ of purified alcohol was added instead of carbazole reagent. The absorbance was read at $525 \mathrm{~nm}$ exactly $15 \mathrm{~min}$. after the addition of acid.

\section{For standards}

About $120.5 \mathrm{mg}$ of galacturonic acid monohydrate was taken in 1 litre volumetric 
flask. To this $10 \mathrm{ml}$ of $0.05 \mathrm{M} \mathrm{NaOH}$ was added and diluted to volume with water. After mixing it was allowed to stand overnight. From this 10,20,40,60 and $80 \mathrm{ml}$ was taken and diluted to $100 \mathrm{ml}$ with water. From this 2 $\mathrm{ml}$ was taken for analysis and standard graph drawn.

$\%$ anhydrogalacturonic acid $=$

$\mu \mathrm{g}$ of anhydrogalacturonic acid in the aliquot $\times$ dilution $\times 100$

$\mathrm{ml}$ taken for estimation $\times$ wt. of pectin sample $\times 1,000,000$

\section{Results and Discussion}

\section{Characterization of fruit wastes}

The fruit wastes were fractionated to assess the biochemical components and the results are presented in table 1 . The results showed that there was appreciable amount of reducing sugars, total sugars, nitrogen, phosphorous, potassium and organic carbon is present in citrus peel, mango peel, banana peel and apple peel respectively

\section{Calorimetric determination and extraction of pectin}

The pectin content of the four fruit wastes was estimated by calorimetric method. The results showed that citrus peel had the maximum pectin content (25.5 per cent) followed by apple pomace (12.5 per cent), mango peel (8.8 per cent) and banana peel (2.8 per cent). The results clearly indicated that citrus peel could be a better source for pectin extraction (Table 2).

The fruit wastes such as citrus peel, mango peel, banana peel and apple pomace were subjected to pectin extraction. The results showed that from citrus peel 24.5 per cent of pectin could be extracted whereas apple pomace, mango peel and banana peel 10.8 per cent, 7.5 per cent and 2.5 per cent respectively could be extracted. From 25.5 per cent of pectin (citrus peel), 24.5 per cent can be extracted. Among the fruit wastes tested, the citrus peel was chosen as the best possible source for the production of pectinase enzyme based on its high pectin content (Fig. 1).

Table.1 Characterization of fruit waste

\begin{tabular}{|c|l|c|c|c|c|c|c|}
\hline S. No. & $\begin{array}{c}\text { Types of } \\
\text { fruit wastes }\end{array}$ & $\begin{array}{c}\text { Reducing } \\
\text { sugar } \\
(\%)\end{array}$ & $\begin{array}{c}\text { Total } \\
\text { sugars } \\
(\%)\end{array}$ & $\begin{array}{c}\text { Total } \\
\text { Nitrogen } \\
(\%)\end{array}$ & $\begin{array}{c}\text { Total } \\
\text { Phosphorous } \\
(\%)\end{array}$ & $\begin{array}{c}\text { Total } \\
\text { potassium } \\
(\%)\end{array}$ & $\begin{array}{c}\text { Organic } \\
\text { carbon } \\
(\%)\end{array}$ \\
\hline 1 & Citrus peel & 8.50 & 17.30 & 4.50 & 0.18 & 0.16 & 28.20 \\
\hline 2 & Mango peel & 12.50 & 28.50 & 2.10 & 0.27 & 0.35 & 23.50 \\
\hline 3 & Banana peel & 10.90 & 18.30 & 3.30 & 0.25 & 0.30 & 20.50 \\
\hline 4 & Apple peel & 9.50 & 13.50 & 2.40 & 0.70 & 0.12 & 18.5 \\
\hline
\end{tabular}

Table. 2 Pectin extraction from fruit wastes

\begin{tabular}{|l|c|c|}
\hline \multicolumn{1}{|c|}{ Source } & Calcium pectate $(\%)$ & Pectin $(\%)$ \\
\hline Citrus peel & 24.5 & 25.5 \\
\hline Mango peel & 7.5 & 8.8 \\
\hline Banana peel & 2.5 & 2.8 \\
\hline Apple pomace & 10.8 & 12.5 \\
\hline
\end{tabular}


The following particulars were done to characterize different fruit wastes

\begin{tabular}{|l|l|l|}
\hline \multicolumn{1}{|c|}{ Particulars } & \multicolumn{1}{|c|}{ Method } & \multicolumn{1}{c|}{ Reference } \\
\hline Reducing sugars & Dinitro salicylic acid & Miller (1972) \\
\hline Total nitrogen & Micro Kjeldahl (Diacid extract) & Humphries (1956) \\
\hline Total phosphorous & $\begin{array}{l}\text { Vanadomolybdate yellow colour in } \mathrm{HNO}_{3} \\
\text { medium (Triple acid extract) }\end{array}$ & Jackson (1973) \\
\hline Total potassium & Flame photometry (Triple acid extract) & Jackson (1973) \\
\hline Organic carbon & Chromic acid wet digestion method & Walkley and Black (1934) \\
\hline
\end{tabular}

Fig.1 Pectin extracted from fruit waste

a) Citrus pectin (Before drying)

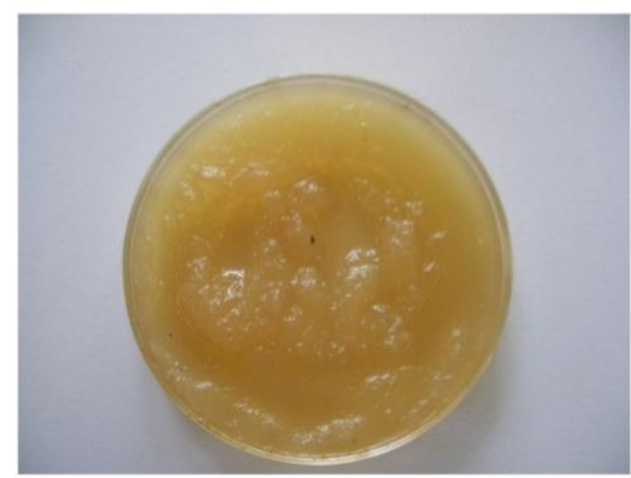

c) Mango pectin (Before drying)

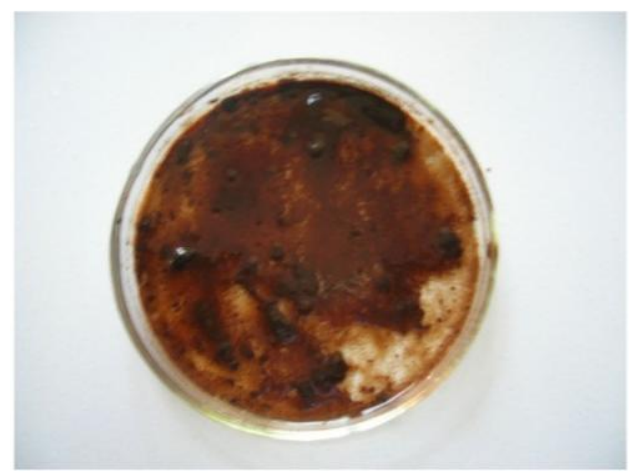

Pectin is a high value functional food ingredient widely used as gelling agent and stabilizer. It is also an abundant ubiquitous and multifunctional component of cell wall of all land plants (William et al., 2005).Pectin is present mainly in fruits of citrus peel, apple, mangoes, banana but commercially it is manufactured from citrus peel and apple b) Citrus pectin (After drying)

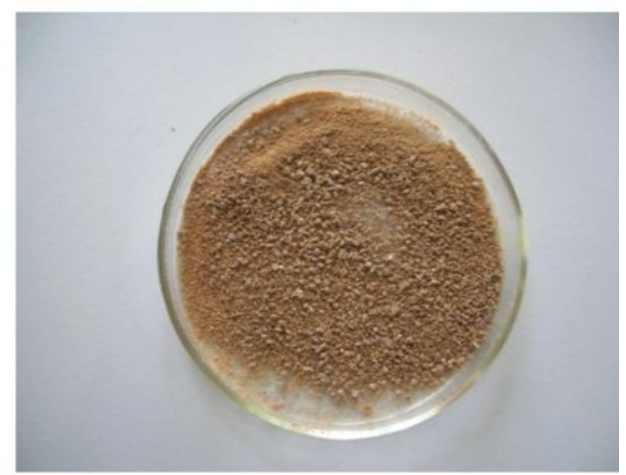

b) Mango pectin (Before drying)

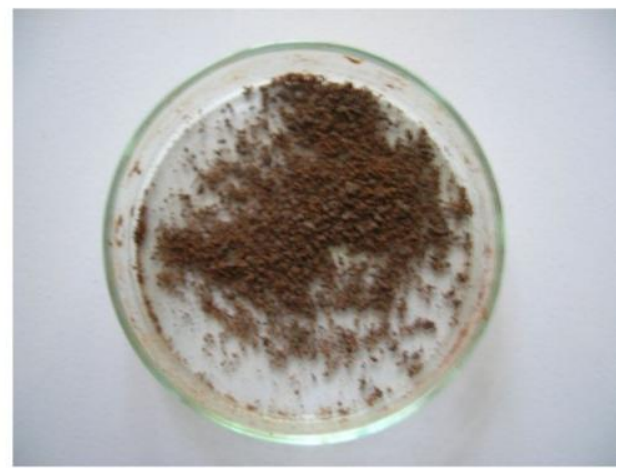

pomace which are the waste products of citrus and apple processing industries (Smock and Neubert, 1950).

In our study also although all the fruit wastes (citrus, mango, banana and apple pomace) had pectin, citrus peel alone had the maximum pectin content of 25.5 per cent and 
also when subjected to pectin extraction with $\mathrm{HCl}$, about 24.5 per cent could be extracted which, account for more than 98 percent recovery. A wide range of reagents could be used for the extraction of pectin. But hydrochloric acid is the most widely used reagent for extraction of pectin from various sources and cost wise also $\mathrm{HCl}$ is cheaper than other organic acids (Sudhakar and Maini, 1995).

In conclusion, fruit wastes such as citrus peel, mango peel, apple pomace and banana peel were subjected to pectin extraction and the results revealed that citrus peel is containing higher pectin content of about $24.5 \%$. Since the citrus peel was found to contain appreciable quantity of pectin, further studies can be conducted to isolate pectinolytic enzyme producing microbes from citrus waste.

\section{References}

Anuradha R., A.K. Suresh and K.V. Venkatesh. 1999. Simultaneous saccharification and fermentation of starch to lactic acid. Process Biochem, 35:367-375

Baker, J.O., C.I. Ehrman, W.S. Adney, S.R. Thomas and M.E. Himmel. 1998. Hydrolysis of cellulose using ternary mixtures of purified cellulases. Appl. Biochem. Biotechnol. 70, 395-403

Hermann, G. 1919. Verber diekohlemhydrate deszukerribenmarke. Z. Ver. Dent. Zuckerind, 69: 233-272.

Humphries, E.C. 1956. Mineral components and ash analysis. Springer - Verlag, Berlin, 1: 468-562.

Jackson, M.L. 1973. Soil chemical analysis. Prentice Hall of India Private Ltd., New Delhi.

Kulkarni, S.G. and Vijayanand, P. 2010. Effect of Extraction Conditions on the Quality Characteristics of Pectin from
Passion Fruit Peel (Passiflora Edulis F. Flavicarpa L.). Food Science and Technology 43, 1026-1031

Laufenberg, G., B. Kunz and Nystroem, M. 2003. Transformation of vegetable waste into value added products: (A) the upgrading concept; (B) practical implementations. Bioresource Technology, 87(2): 167-198.

Manickam, A. and S. Sadasivam. 1996. In: Biochemical methods, New Age International (P) Ltd., Publishers, New Delhi., pp. 18-19.

May, C. D. 1990. Industrial pectins: sources, production and applications. Carbohydrate Polymers 12(1): 79-99.

Miller, G.L. 1972. Use of dinitrosalicylicacid reagent for the determination of reducing sugars. Anal. Chem., 31: 426428.

Minjares-Fuentas, R., A. Femenia, M.C. Garau, J.A. Meza-Velazquez, S. Simal and C. Rossello, 2014. UltrasoundAssisted Extraction of Pectins from Grape Pomace using Citric Acid: A Response Surface Methodology Approach. Carbohydrate Polymers 106: 179-180.

Pagan J., A. Ibarz, M. Llorca, a Pagan and G.V. Barbosa-Canovas 2001. Extraction and characterization of pectin from stored peach pomace, Food Research International. 34: 605-612.

Parfitt, J., M. Barthel and Macnaughton, S. 2010. Food waste within food supply chains: quantification and potential for change to 2050. Philosophical Transactions of the Royal Society of London B: Biological Sciences, 365(1554): 3065-3081

Pinheiro, E.R., I.M.D.A. Silva, L.V. Gonzaga, E.R. Amante, and M.M.C., Amboni, 2008. Optimization of Extraction of High-Ester Pectin from Passion Fruit Peel (Passiflora edulis Flavicarpa) with Citric Acid by using Response Surface 
Methodology. Bioresourse. Technology 99: 5561-5566

Smock, R.M. and Neubert. A.M. 1950. Apple and apple products, Interscience Public inc., New York., pp. 19-50.

Sudhakar, D.V. and Maini. S.B. 1995. Pectins from fruit processing waste a review. Ind. Fd. Packer., 49 (1): 39-45.

Walkley, A. and Black. C.A. 1934. An examination of the (Degtijareff) method for determining soil organic matter and a proposal modification of chromic acid titration method. Soil. Sci., 37: 93-101.

Williams, P. A., C. Sayers, C. Viebke, C. Senan, J. Mazoyer and P. Boulenguer, 2005. Elucidation of the emulsification properties of sugar beet pectin. Journal of Agricultural and Food Chemistry. 53: 3592-3597.

\section{How to cite this article:}

Panchami, P.S. and Gunasekaran, S. 2017. Extraction and Characterization of Pectin from Fruit Waste. Int.J.Curr.Microbiol.App.Sci. 6(8): 943-948. doi: https://doi.org/10.20546/ijcmas.2017.608.116 